\title{
A filosofia do "chegar a ser o que se é" no jovem-Nietzsche enquanto pratica didática do filosofar: reflexões para o professor de ensino médio de escola pública ${ }^{1}$
}

\author{
The philosophy of "becoming what one is" in the young-Nietzsche as a \\ didactic practice of philosophizing: reflections for the public school high \\ school teacher
}

\section{Wellington Santos}

Professor mestrando da Universidade Federal de Mato Grosso do Sul, MS, Brasil. weellingt@hotmail.com - https://orcid.org/0000-0002-9965-2222

Recebido em 27 de agosto de 2021

Aprovado em 15 de novembro de 2021

Publicado em 30 de dezembro de 2021

RESUMO: Aborda-se nesta investigação o ensino de filosofia tendo como função a formação de capital moral crítico a partir do jovem-Nietzsche. Busca-se, com isso, interpretar o conceito nietzscheano de educação integral expresso pela fórmula "como chegar a ser o que se é" e comparálo com a noção de formação integral normatizado pela Base Nacional Comum Curricular (BNCC) a fim de situar o componente curricular de filosofia nesta crise de paradigma curricular. Desse modo, nossa análise, fundamentada por revisão bibliográfica e análise documental específica, identifica que a formação filosófica constitui-se parte indispensável da Formação Cultural do educando no ensino médio de escola pública.

Palavras-chave: jovem-Nietzsche; capital moral crítico; BNCC, formação cultural.

ABSTRAC: In this investigation, the teaching of philosophy is approached, having as its function the formation of critical moral capital from the young-Nietzsche. The aim is, therefore, to critically interpret the Nietzschean concept of integral education expressed by the formula "how to become what one is" and to compare it with the notion of integral education standardized by the Common National Curriculum Base (BNCC) in order to situate the curricular component of philosophy in this crisis of the curricular paradigm. In this way, our analysis based on a bibliographical review and specific documental analysis identifies that the philosophical formation constitutes an indispensable part of the Cultural Formation of the student in the high school of public school.

Keywords: young-Nietzsche; critical moral capital; BNCC, cultural formation. 


\section{Introdução}

Os principais textos de Friedrich Wilhelm Nietzsche (1844-1900) sobre o tema Ensino de Filosofia e o que se problematiza aqui por sua Filosofia da Educação são os escritos de juventude para a conferência no "AkademischesKunstmuseum" Sobre o futuro de nossos estabelecimentos de ensino ${ }^{2}$ proferida em 1872, discurso, inclusive, expressado literalmente enquanto Romance de Formação (Bildungsroman $)^{3}$ entre o "filósofo e seus aprendizes" - e a Terceira Extemporânea:4 Schopenhauer como educador de 1874 ao se posicionar contra o reducionismo da formação escolar de Ensino Médio (Gymnasium) aos interesses mercantis do capitalismo nascente.

A reflexão nietzscheana "qual o preço disposto a pagar por pertencer a si mesmo" - de acordo com o professor Larrosa (2009), ilustra o processo pedagógico de 'subjetivação' desta filosofia enquanto 'luta entre o convencionalismo do agrupamento e a ânsia de singularidade do indivíduo [...] na qual perdem os preguiçosos e os covardes" (p. 49), isto é: o problema como chegar a ser o que se $e^{5}$. Porém, tal resposta como possível condição para a "afirmação de si mesmo" antecede outra indagação: qual o valor da vida?

A questão é que o ensino de filosofia nos estabelecimentos de ensino alemão em sua época, indaga o jovem-Nietzsche (2003), não preparava o estudante para a vida - "mas somente para uma prova de filosofia, cujo resultado, já se sabe, é normalmente que aquele que sai desta prova confessa para si com um profundo suspiro de alívio: graças a Deus, não sou um filósofo" (p. 213). Sobre esta centralidade do valor-vida no pensamento nietzscheano, Safranski (2001) denomina didaticamente Filosofia da Vida a corrente filosófica-literária desencadeada pelo autor: sugerindo que filosofar, de acordo com este projeto, significa tornar o viver continuamente potência criativa, artística e conceitual de aprendizagem.

Para pensar com o jovem-Nietzsche tal temática é importante compreender que - enquanto professor de filologia na Basileia - participou do principal debate pedagógico de sua época, a saber: o que é uma Educação Integral do jovem alemão? Ou melhor: o que é uma autêntica Formação Cultural (bildung ${ }^{6}$ que possa 
ser praticada nos estabelecimentos de ensino público? As respostas do professor são pertinentes porque ilustra o seguinte problema atual brasileiro que se busca, a seguir, comparar criticamente e propor como chave-interpretativa: qual a situação da filosofia nesta crise de paradigma curricular pós-aprovação da Base Nacional Comum Curricular (BNCC)?

\section{Filosofia, currículo e BNCC}

Para o jovem-Nietzsche, o Ensino de Filosofia constitui-se - ao lado da ciência e da arte - componente curricular obrigatório no Ensino Médio considerando a Formação Cultural enquanto processo de socialização, sinequa non, do educando em pleno desenvolvimento; a partir disso, o autor também defende uma Educação Integral que nos permite ponderar sobre as principais diretrizes políticas, especificamente, o que se referencia por "formação integral" e o papel da formação filosófica nesta etapa de ensino.

Como se sabe, etimologicamente, o termo "educação" vem de educare (conduzir, guiar, orientar) e educere (fazer sair, extrair, dar à luz) - e de acordo com a BNCC (2018), a concepção curricular de Educação Básica (infantil, fundamental e médio) hoje no Brasil deve assegurar o desenvolvimento orgânico e progressivo de "aprendizagens essenciais" e "dez competências gerais" (p. 09-10) do educando em contraste com um currículo, até então, julgado conteudista.

O Art. $5^{\circ}$ da Resolução $n^{\circ} 3$, de 21 de novembro de 2018, que atualiza as Diretrizes Curriculares Nacionais para o Ensino Médio e fundamenta a BNCC, assim como orienta os sistemas de ensino e unidades escolares na organização curricular - tendo em vista as alterações introduzidas na Lei $n^{\circ} 9.394$ (LDB) pela nova Lei •13.415/2017, afirma que o Ensino Médio em todas as suas modalidades de ensino e as suas formas de organização e oferta, deverá ser orientado, entre outros dispositivos, pelos seguintes princípios específicos:

I - formação integral do estudante, expressa por valores, aspectos físicos, cognitivos e socioemocionais; 
II - projeto de vida como estratégia de reflexão sobre trajetória escolar na construção das dimensões pessoal, cidadã e profissional do estudante.

O Art. $6^{\circ}$, para fins de obtenção de maior clareza de exposição, ficam definidos os seguintes termos utilizados na presente Resolução:

I - formação integral: é o desenvolvimento intencional dos aspectos físicos, cognitivos e socioemocionais do estudante por meio de processos educativos significativos que promovam a autonomia, o comportamento cidadão e o protagonismo na construção de seu projeto de vida.

Ou seja, vale a citação literal da lei porque há o entendimento mútuo entre formação integral e projeto de vida em relação aos princípios orientativos curriculares; com isso, almeja-se apontar duas críticas à BNCC e um elogio: primeiro, o aspecto positivo da valorização socioemocional fazendo parte da formação do educando frente à complexidade (líquida) das relações sociais e de identidade (subjetividade) na sociedade contemporânea. Porém, antes de tal pretensão, para alocar bem o entendimento da argumentação, perceba-se mais detalhadamente do que se trata este documento normativo, diversificado e flexível: composto estruturalmente por Formação Geral Básica e Itinerários Formativos.

Na BNCC, competência é definida como a mobilização de conhecimentos (conceitos e procedimentos), habilidades (práticas, cognitivas e socioemocionais), atitudes e valores para resolver demandas complexas da vida cotidiana, do pleno exercício da cidadania e do mundo do trabalho (BNCC, 2018, p. 8).

Esse novo arranjo curricular e concepção de Educação Básica sob o pretexto da criação de alternativas que superem a fragmentação do conhecimento busca normatizar abordagens de "atividades integradoras interdisciplinares", isto é, o intercâmbio entre unidades curriculares (diga-se as antigas disciplinas) por meio da ação didática mediada pela pedagogia de projetos temáticos: esta é a nova adoção teórica e prática da política educacional brasileira.

Partindo dessa situação, a organização curricular dos sistemas de ensino e unidades escolares devem se estruturar pela flexibilização e o tratamento metodológico que favoreça e estimule o "protagonismo estudantil": procedimentos 
que evidenciem, assim, a contextualização, a diversificação e a "transdisciplinaridade" (BNCC, 2018, p. 479). De modo geral, o Ensino Médio passa a ser organizado em quatro áreas do conhecimento (Linguagens e suas Tecnologias, Matemática e suas Tecnologias, Ciências da Natureza e suas Tecnologias, Ciências Humanas e Sociais Aplicadas) - onde apenas o componente curricular de Língua Portuguesa e Matemática são obrigatórios nos três anos dessa etapa.

Porém, o texto ressalta que não se exclui "teoricamente" as outras "disciplinas", com suas especificidades e saberes próprios historicamente construídos, mas indica reforçar "o fortalecimento das relações entre elas e a sua contextualização para apreensão e intervenção na realidade" (BNCC, 2018, p. 32): exigindo que os sistemas de ensino e as escolas construam os currículos e propostas pedagógicas flexíveis e adequados à sua realidade.

llustrando o raciocínio, consideram-se os seguintes temas-conceituais importantes em relação às aprendizagens a ser garantidas mediante estas abordagens integradoras aos jovens, de acordo com a BNCC (2018, p. 562), na área de Ciências Humanas e Sociais Aplicadas (CHSA) - aqueles julgados essenciais à formação dos educandos e às competências específicas de filosofia que agora estão ligadas às "competências gerais" da área:

- Tempo e Espaço;

- Territórios e Fronteiras;

- Indivíduo, Natureza, Sociedade, Cultura e Ética;

- Política e Trabalho.

Considera-se, também de modo geral, que os componentes curriculares dessa área possuem mesma necessidade formativa em relação aos conteúdosconceituais e convergem para as mesmas habilidades ${ }^{7}$ e competências, norteados pela busca de justiça social, autonomia, equidade e respeito às diferenças e relacionados com a finalidade desta etapa de ensino médio.

Contudo, chama-se crise de paradigma curricular toda esta fragilização, em especial, das ciências humanas que teve início com o racionalismo científico 
moderno e o descrédito da filosofia e da problematização epistemológica e axiológica. Conforme se lê na Terceira Extemporânea - Schopenhauer como Educador (2020) "mesmo a forma muito admirada, com a qual os eruditos alemães se precipitam sobre sua ciência, mostra sobretudo que eles pensam mais na ciência que na humanidade" (p. 11).

Primeira crítica: a meu ver, esta nova estrutura curricular que se apresenta (Lei $\mathrm{n}^{\circ} 13.415 / 2017$ ) por atividades integradoras e projetos temáticos (denominado pedagogia de projetos temáticos) incorre pelo vacilo de reduzir as aulas de filosofia num espaço-tempo pouco significativo em termos de Formação Cultural do educando. Primeiro porque o atrativo do trabalho temático pode se tornar entretenimento, ou quando muito - transmissão de informação em nome da contextualização (inclusive, adoção de livros didáticos assim arranjados). E segundo porque se supervaloriza o protagonismo estudantil e joga-se em segundo plano o debate da "formação docente" (e continuada também) desse profissional de escola pública, especificamente, sobre o surgimento ou reforço de programas de extensão (por exemplo, o Programa Institucional de Bolsas de Iniciação à Docência), estágios supervisionados e/ou residência pedagógica etc., dado que agora nem competência específica a filosofia possui oficialmente. Daí a necessidade de bagagem culturalfilosófica do educador conjugado com sua experiência prática (e clareza) sobretudo às indagações "que fins pretendo alcançar com minhas aulas?" "Qual filosofia/filosofar propor aos educandos?"

Segunda crítica: para superar o "conteudismo curricular" estanque se propõe o ensino teórico-metodológico pautado por eixos temáticos (na forma de projetos interdisciplinares sob os quatro temas-conceituais acima): e sobre isso, compreendese o defeito limitador do ensino de filosofia ao desconsiderar o referencial, mínimo, teórico e histórico da abordagem filosófica ajustado à sua carga horária de trabalho efetivo $^{8}$. Não se está defendendo o tradicionalismo pedagógico, mas é importante e indispensável a estruturação de algum conteúdo curricular - outro desafio para o professor que exigirá astúcia conjugada com experiência.

Ou seja, tal organização curricular por eixos e projetos temáticos como condicionantes exclusivos para ensinar o filosofar, incorre como já dito, no perigo 
das aulas de filosofia tornarem-se um bate papo informal sem referência dos clássicos da área; dado que também pratica-se e aprende-se filosofia ao interpretar, por exemplo, a "história do pensamento" (escolas, correntes, etc.) - ou se apropriando, contextualizando, problematizando e adaptando a teoria de dado (a) filósofo (a) para outro contexto: como argumentará o jovem-Nietzsche.

E qual seria, então, a justificativa/contribuição para a presença da filosofia enquanto componente curricular (ou projeto dentro dos Itinerários Formativos) no Ensino Médio? Indica-se, primeiramente, a formação antropológico-filosófica específica tendo as "escolas ou filósofos" como sistema e parâmetro conceitual; em segundo, a formação política da filosofia no sentido que filosofar é intervir na realidade modificando-a: e como disciplina espécie de vigia-dos-vigilantes, ela desempenha a crítica epistemológica da atitude científico-tecnológica dado os eventuais problemas globais; enquanto transdisciplina, ela é axiológica e orienta "o que" e "como" o homem pode agir, isto é, a filosofia é inquestionavelmente crítica e valorativa.

Portanto, dado o entendimento de formação integral e "projeto de vida" minha hipótese é a possibilidade da filosofia (pela sua especificidade) ser "jogada" para ser trabalhada como complemento de carga horária no componente curricular (disciplina) projeto de vida. Se isso for vivido empiricamente, a filosofia nietzscheana "chegar a ser o que se é" será um programa de curso alternativo para ser experimentado. Pois, "chegar a ser o que se é" remete-se a própria noção de Educação Integral para o jovem-Nietzsche, isto é, processo pedagógico-e-filosófico de formação (I) intelectual, (II) moral, (III) estético e (IV) contínuo do educando em pleno desenvolvimento, especialmente, conforme explica o professor Larrosa (2009, p. 45) - pela doação de sentido e valor à vida ${ }^{9}$ por meio da "cultura autêntica", ou seja: "processo temporal pelo qual um indivíduo alcança sua própria forma, constitui sua própria identidade, configura sua particular humanidade ou, definitivamente, converte-se no que é".

Cabe agora compreender o papel da formação filosófica para "chegar a ser o que se é" enquanto "projeto de tornar-se livre" tornando o viver continuamente potência criativa, artística e conceitual de aprendizagem. 


\title{
O ensino de filosofia tendo como função a formação de capital moral crítico
}

Contra a tendência moderna de massificação do utilitarismo e liberalismo inglês que associa cultura, mercado e consumo - o jovem-Nietzsche defende o "princípio capital de toda cultura" (2003, p. 59), onde escola e, consequentemente, o ensino de filosofia tem como função a formação de "capital de moralidade acumulado por nossos ancestrais e da herança deles, que não sabemos mais fazer crescer, mas somente dissipar" (2003, p. 145).

\begin{abstract}
Como a vida do indivíduo [...] adquire o supremo valor, a mais profunda significação? Certamente, apenas por meio disto: que tu vivas para o proveito dos exemplares mais raros e valiosos, e não para o proveito da maioria, [...] essa orientação deveria ser implantada e cultivada num jovem, de modo que ele próprio se compreenda como que uma obra malograda da natureza, e ao mesmo tempo como um testemunho das mais excelsas e maravilhosas intenções dessa artista (NIETZSCHE, 2020, p. 64).
\end{abstract}

Portanto, o ensino de filosofia para o jovem-Nietzschetem a História da Filosofia como referencial teórico de verdadeira "cultura autêntica" para o educando criar sua própria diretriz de pensamento e interrogação, isto é: experimentar sua autoformação hermeneuticamente e se desenvolver na medida em que compreende, se apropria, problematiza, contextualiza e reformula as questões conceituais - cujo objetivo é exercer a "crítica dos costumes, das leis e dos valores existentes, quer dizer, o ataque à mentalidade mercantil que vincula cultura e dinheiro e à mentalidade estatal que instrumentaliza as instituições de ensino para seu próprio proveito" (2003, p. 38).

Com isso, indica-se a necessidade do professor - inicialmente, "alfabetizar filosoficamente" o estudante para ele 'aprender lendo' de modo analítico os mais diversos textos e registros, podendo aplicar os seguintes passos didáticos quando trabalhado o texto na forma de esquema estratégico:

- Análise textual-etimológica da obra ou recorte (esclarecimento semântico por meio de pesquisa bibliográfica e/ou dicionário);

- Análise temática-conceitual (identificar o tema-central, o problema e a tese 
do autor);

- Análise interpretativa ou perspectivista (diálogo-crítico com o texto recriando os conceitos de acordo com a bagagem cultural do experimentador);

- Análise problemática (capacidade hipotética de relacionar ou contrapor conceitos de modo contextualizado);

- Síntese pessoal (ponto de vista discursivo e argumentação retórica sobre o exposto).

Compreenda-se que doação de sentido à vida pela cultura autêntica passa do processo de (I) formação intelectual à atitude negativa "crítica dos costumes, das leis e dos valores" para depois afirmar si mesmo. Em contexto, importante situar que a crítica educacional do jovem-Nietzsche dirige-se especialmente à tradição kantiana e hegeliana quando abordado a questão "filosofia, ensino e método histórico" (2003) e a influência que estes tinham sobre o currículo dos estabelecimentos de ensino no aspecto de formação moral e para o dever: a seu ver, perigoso pelo proselitismo ideológico (doutrinário) conforme a natureza pedagógica de passividade de tal abordagem: formando, consequentemente, o filisteu da cultura jornalística (especialista em opiniões e da moda). Por isso, a proposta pedagógica de um filosofar com o martelo moral des-construtivo em relação a ideais dogmáticos e contra a tendência formativa de "valores" massificadores do rebanho.

Para o jovem-Nietzsche, o educador ensina filosofia - filosofando, especialmente, ao alfabetizar o educando pela linguagem-filosófica e partir esquematicamente do texto como ponte metodológica adaptando um "discurso pedagógico" pela qual a tradição possa tornar-se "saber ensinável-e-compreensível"; portanto, contra o método histórico passivo e cômodo:

Agora se trata de estabelecer o que pensou ou não este ou aquele filósofo, se é possível com razão atribuir a ele este ou aquele escrito, ou se esta ou aquela lição merece ser retida... nossos estudantes são dirigidos a este tratamento neutro da filosofia (NIETZSCHE, 2003, p. 129).

Mediante a exposição dialógica, o debate, o filme, a música, a obra de arte, a charge, etc., é possível provocar didaticamente o educando a ele mesmo "chegar a 
ser o que se é”, isto é, por meio de metodologias ativas e não neutras; ou pode-se pergunta o jovem-Nietzsche (2020): “obrigar violentamente para a música alguém que tem uma inclinação decidida para a ourivesaria?" (p. 09), ou ainda, para a filosofia alguém que tem inclinação para a astronomia e assim por diante.

Sobre isso, o professor Cerletti (2004) defende que falar em "métodos eficientes ou eficazes" sobre o ensino de filosofia é, "tão-somente exercitar algumas instruções programáticas. [...] esquemas operacionais ou estratégias pedagógicas" (p. 40) - que dependerá das decisões do educador quando planejar suas aulas em relação ao que compreende e qual "o sentido" que atribui a seu ofício, ou seja, discutir um tema (filósofo ou escola, por exemplo) implica ser interrogado por ele, significa expor-se nele e por isso a prática docente é um constante autoformar-se, tornar-se educador.

Sobre a (II) formação moral, a partir de uma sugestão de Deleuze (1987) interpreta-se este processo de aprendizagem e proposta comparando-o com o ofício de um "egiptólogo": isto é, filosofar é um decifrar/produzir signos socioculturais (conceito) de vida histórica, sintagmático, conectivo e vicinal,pois tudo o que nos ensina alguma coisa emite signos, consequentemente, todo ato de aprender é uma interpretação de significados que em Nietzsche liga-se a questão da "genealogia dos valores".

\footnotetext{
Tua essência autêntica não está profundamente oculta, mas imensamente acima de ti ou, pelo menos, acima daquilo que tu habitualmente presumes ser teu eu. Teus educadores e formadores autênticos adivinham em ti qual é o sentido [...] de tua essência, algo inteiramente não educável e não formável, mas em todo caso de difícil acesso. Teus educadores nada mais podem ser que teus libertadores (NIETZSCHE, 2020, p. 08).
}

Logo, a tarefa metodológica do educador quando abordado a História da Filosofia é a competência ao filosofar "interpretar e avaliar" os fenômenos-valorativos considerando, esclarece Deleuze (1976), que essa "arte de interpretar deve ser também uma arte de romper as máscaras, e de descobrir quem se mascara e porquê, e com que sentido se conserva uma máscara remodelando-a" (p. 5); em poucas palavras: o genealogista determina a hierarquia social dos valores;cuja formação de capital moral crítico depende também desse "impulso pedagógico" não 
apenas analítico histórico, mas também demonstrando-se a emergência do problema presente - por vias até então despercebidas.

Ou seja, tal procedimento negativo assume, primeiramente, a atitude de se opor em aceitar o caráter absoluto dos valores tanto quanto a seu caráter relativo ou utilitário; e para isso, Deleuze (1976) afirma que Nietzsche conceitua "vontade de potência" (ou poder) o elemento diferenciador dos valores: "é da vontade de potência, como elemento genealógico, que derivam a significação do sentido e o valor dos valores" (p. 27) - onde este conceito determinaria como uma "força prevalece sobre outras, domina-as ou comanda-as" historicamente considerando nossas relações socioculturais, políticas ou econômicas: dessa forma, lê-se em Genealogia da Moral (2009) que o sentido histórico deve ser investigado pela "teoria de uma vontade de poder operante em todo acontecer" (p. 62).

Sobre o terceiro aspecto, a formação estética (III) constitui papel decisivo para a educação integral do educando por ser a consolidação da sensibilidade trágica ${ }^{10}$ : aprendizagem e cultivo de si pelas "sensações dionisíacas" enquanto pulsão "éticoestético" da existência.

O indivíduo deve se consagrar a algo suprapessoal - assim quer a tragédia; ele deve desaprender a angústia terrível que Ihe inspira a morte e o tempo: pois, no mais breve instante, no mais ínfimo átomo do curso de sua vida ele pode encontrar algo sagrado que compense abundantemente toda luta e toda necessidade - isso significa ter o sentido trágico (NIETZSCHE, 2009, p. 26).

Este sentido trágico é importante para o jovem-Nietzsche porque prepara o aprendiz para a dramaticidade, o absurdo e o problemático da vida. "Para um ensino de filosofia do caos e da força: uma leitura à luz da filosofia nietzschiana" (2004) o professor Danelon esclarece, neste artigo, que a filosofia para Nietzsche é uma aprendizagem para aqueles que possuem - "a força de espírito para a solidão, para o enfrentamento do medo" e "que não se submetem à segurança dos ideais" ( $p$. 348), ou melhor: 
O ensino de filosofia inspirado na filosofia nietzscheana tem em seu horizonte a promoção de uma atitude humana em que os momentos de crises, solavancos, vicissitudes e contingências inerentes à existência sirvam de alimento para a potencialização do próprio homem (DANELON, 2004, p. 350).

Em síntese, filosofia de vida que afirma: prepara-te para o pior; como material didático sugestivo e contando com a experiência, (re)formulação e adaptação pelo educador atuante em sala, pode-se pesquisar, por exemplo, para ser trabalhado pedagogicamente a tragédia As Bacantes, de Eurípedes; os coros de Ésquilo e Sófocles, os heróis trágicos da mitologia grega, (Moira, Orestes, Sísifo, etc.), a experimentação da música de Richard Wagner (O Anel do Nibelungo), o poema $O$ Bicho, de Manuel Bandeira, O Tempo, de Mário Quintana, Saber viver, de Cora Coralina, Se eu morresse amanhã, de Álvares de Azevedo, Singular ocorrência, de Machado de Assis.

\section{Considerações Finais}

Pode-se caracterizar o filosofar do jovem-Nietzsche e sua relação com a formação "chegar a ser o que se é", didaticamente, por três aspectos que simboliza tal relação processual: o político (capital moral crítico), o estético (sensibilidade trágica) e o antropológico enquanto afirmação da liberdade.

É certo compreender que a formação filosófica nietzscheana ao se constituir necessária para a Formação Cultural do educando em pleno desenvolvimento, é de caráter emancipador no sentido de consciência e aprendizado em saber conjugar suas aspirações com o julgamento e a moralidade dos costumes, das leis e dos valores massificados para a subserviência.

Nesse sentido, viver a liberdade ao "chegar a ser o que se é" é "aprender a desprender-se": tornar-se resiliente intelectual e socioemocionalmente, condição que o professor Larrosa (2009, p. 09) explica "como o ponto em que o sujeito lança-se além de si mesmo para que algo novo possa aparecer", ir além do que somos, invenção de novas possibilidades. 
A verdadeira tarefa do educador-moral ao forçar o desenvolvimento das virtudes do educando para que ele possa aprender, desaprender e reaprender ao longo da vida, a partir da prática metodológica da genealogia dos valores quando abordado a História da Filosofia com a finalidade de impulsionar "aquilo para o qual algo foi feito"- é ele mesmo, neste processo relacional, ser superado pelo educando: o aprendiz que aprende a pensar por si mesmo e, portanto, supera o mestre quando passa a viver as potencialidades humanas em plenitude.

Para isso se realizar, a prática docente não pode reforçar a moral de rebanho, isto é, a "reprodução do ascetismo" ideológico-doutrinário, religioso ou filosófico. Além deste problema, para o jovem-Nietzsche (2003) o educador-filósofo tem outros três desafios que exige aquela atitude negativa: 1) o egoísmo capitalista que fomenta a cultura de massa, incluindo necessidade, produção, lucro e felicidade no mesmo carrinho de compra; 2) o egoísmo do Estado ao representar e conservar os interesses utilitários e submissão ao poder da Indústria Cultural; 3) e o egoísmo da ciência ao idealizar-se enquanto valor absoluto de verdade.

\section{Referências}

BRASIL. Ministério da Educação. Base Nacional Comum Curricular. Brasília, 2018.

CERLETTI, A. Ensinar Filosofia: da pergunta filosófica à proposta metodológica. In: KOHAN, Walter O. (org). Filosofia: caminhos para seu ensino. Rio de Janeiro: DP\&A, p.19-43, 2004.

DELEUZE, G. Nietzsche e a Filosofia. Trad. Ruth Joffily Dias e Edmundo Fernandes Dias. Rio de Janeiro, ed. Rio, 1976.

DELEUZE, G. Proust e os signos. Rio de Janeiro: Forense Universitária, 1987.

DANELON, M. Para um ensino de filosofia do caos e da força: uma leitura à luz da filosofia nietzschiana. Cad. Cedes, Campinas, vol. 24, n. 64, p. 345-358, set./dez. 2004.

GIACOIA, Oswaldo. Nietzsche. São Paulo, Ed. Publifolha, 2000.

LARROSA, Jorge. Nietzsche \& a Educação. Traduzido por Semíramis Gorini da Veiga, $3^{\circ}$ ed, Belo Horizonte, Edi. Autêntica, 2009. 
MARTON, S. Dicionário Nietzsche, São Paulo, Edições Loyola (Sendas \& Veredas), 2016.

NIETZSCHE, Friedrich. Escritos sobre Educação. Tradução, apresentação e notas Noéli Correia de Melo Sobrinho, Rio de Janeiro, Ed. PUC-Rio, 2003.

NIETZSCHE, Friedrich. Genealogia da Moral: uma polêmica. Tradução de Paulo Cesar de Souza, São Paulo, Ed. Companhia das Letras, 2009.

NIETZSCHE, Friedrich. Schopenhauer como educador: Consideração extemporânea III. Trad. Clademir Luís Araldi, São Paulo, Ed. WMF Martins Fontes, 2020.

NIETZSCHE, Friedrich. Wagner em Bayreuth. Trad. de Anna Hartmann Cavalcanti. Rio de Janeiro: Jorge Zahar, 2009.

Safranski, R. Nietzsche: biografia de uma tragédia. Trad. Lya Luft. São Paulo: Geração Editorial, 2001.

\section{Notas}

${ }^{1}$ Este artigo reúne as principais conclusões da pesquisa intitulada "A ideia de formação cultural (bildung) no jovem-Nietzsche enquanto prática didática para o filosofar" defendida no curso de Mestrado Profissional do Programa de Pós-graduação em Filosofia (PROF-FILO), núcleo Universidade Federal de Mato Grosso do Sul (UFMS).

${ }^{2}$ Com 28 anos de idade e professor de filologia clássica na Universidade da Basileia escreve este livro cuja crítica dirige-se aos ideais políticos e pedagógicos da sociedade moderna alemã defendendo o "renascimento" da cultura grega antiga; onde educação e escola são compreendidas como memória viva de um povo para a formação e para o futuro da "cultura autêntica".

${ }^{3}$ Corrente-literária inicia por W. von Goethe em Os anos de aprendizado de Wilhelm Meister(1795); tipo de prosa que retrata o desenvolvimento psicológico, espiritual, social, político ou cultural de um protagonista. No caso Nietzsche, também CF. Assim falava Zaratustra (1883).

${ }^{4}$ Nietzsche escreveu quatro Considerações Extemporâneas de 1872 a 1876: "David Strauss como apóstolo e escritor"; "Da utilidade e desvantagens da história para a vida"; "Schopenhauer Educador" e "Richard Wagner em Bayreuth".

\footnotetext{
5“Wiemanwird, wasmanist" frase inspirada numa passagem da II Ode Pítica de Pindáro que ficou particularmente conhecida como o subtítulo da autobiografia de Nietzsche publicada em 1888, Ecce homo: cuja expressão exprime a concepção que todo educar remete-se a um processo de autoformação.

${ }^{6}$ Projeto político pedagógico encabeçado especialmente por Wilhelm von Humboldt pela Reforma das Instituições Escolares concretizando-se na fundação da Universidade de Berlim em 1810. O conceito bildung (formação, autoformação, cultivo de si) está intimamente relacionado com a noção grega de Paideia, a qual busca estruturar o ideal formativo intelectual e de excelência humana para o cidadão. Sobre isso, CF. WEBER. J. F. Bildung e Educação. Rev. Educação \& Realidade, Porto Alegre, 31(2): 117-134, juln./dez. 2006.
} 
${ }^{7}$ Art. $5^{\circ}$ da Resolução $n^{\circ} 3$ : VII - habilidades: conhecimentos em ação, com significado para a vida, expressas em práticas cognitivas, profissionais e socioemocionais, atitudes e valores continuamente mobilizados, articulados e integrados.

${ }^{8}$ Aqui se apresenta o currículo oculto do trabalho docente em escola pública - dado que este componente curricular possui apenas uma aula por semana de cinquenta minutos, restringida, ainda, apenas na etapa do ensino médio como estabelece o currículo regional: quantidade/turma professor (quarenta/cinquenta alunos por sala), infraestrutura precarizada, carência de recursos tecnológicos, multiemprego por escolas, plano de carreira, remuneração etc. etc. etc.

${ }^{9}$ Em suas obras Nietzsche relaciona vida à constante luta; "e com a luta, estabelecem-se hierarquias: a cada momento, determinam-se vencedores e vencidos, senhores e escravos, os que mandam e os que obedecem. [...] A partir daí, a noção de vida aparecerá estreitamente ligada à de valor e ocupará um lugar central no procedimento genealógico. [...] é a vida, enquanto vontade de potência, que adota como critério de avaliação das avaliações" MARTON, S. Dicionário Nietzsche, São Paulo, Edições Loyola (Sendas \& Veredas), 2016, p. 412.

${ }^{10}$ Tema abordado no livro O Nascimento da Tragédia de 1872 onde se encontra a célebre sentença: "a existência do mundo só se justifica como fenômeno estético".

\section{(1) (1)(9)}

This work is licensed under a Creative Commons Attribution-NonCommercial 4.0 International (CC BY-NC 4.0) 